\title{
Postmodern Yeni Dinsel Kimlik ve Paranormal İnançlar
}

Mustafa ARSLAN*

Postmodern New Religious Identity and Paranormal Beliefs

Citation/@: Arslan, Mustafa, (2015). How Does Postmodernity Exist as a Problematic of Philosophical Consciousness?, Milel ve Nihal, 12 (2), 5572.

Abstract: Today, there is an increase of the interest in the paranormal beliefs and practices. This increase is associated with the search for a new identity in postmodern area. In this paper we associated with the concept of re-enchantment of the world this new identity in postmodern area. Besides we pointed out that the search for this identity has the elements of modern religious individualization and religious pluralism and the search for this identity continue in more advanced forms in the media. We also pointed out that this new identity or re-enchantment of the world has moved in popular culture and the media. The most important role in the functionality of this new identity belongs to the myths and paranormal beliefs. There is a relationship between the human desires of having super paranormal powers and escaping from rational 'iron cage' through popular culture. Besides, popular culture has secular and consumption characteristics take into account individual pleasures. When sacred appears in popular culture, it (sacred) affects by secular and consumption characteristics of popular culture. These paranormal phenomenons intertwined with capitalist consumer culture and they seem to be very well adapted to global communications and consumer tools.

* Prof. Dr., İnönü Üniversitesi, İlahiyat Fakültesi, Din Sosyolojisi Anabilim Dalı [mustafa.arslan@inonu.edu.tr] 
Key Words: postmodern new religious identity, paranormal belief, popular culture, re-enchantment of the world, myth.

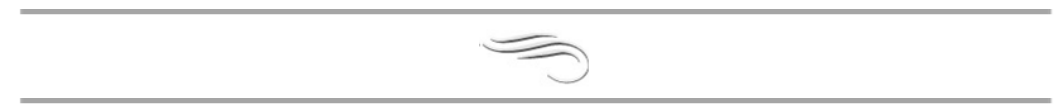

Atıf/C: Arslan, Mustafa, (2015). Postmodern Yeni Dinsel Kimlik ve Paranormal İnançlar, Milel ve Nihal, 12 (2), 55-72.

Öz: Günümüzde paranormal inanç ve uygulamalara ilgide bir artış söz konusudur. Bu yaygınlık postmodern dönemdeki "yeni kimlik" arayışlarıyla bağlantılıdır. Biz bu yazıda postmodern dönemle gelen yeni kimlikleri "dünyanın yeniden büyülendirilmesi" kavramı ile ilişkilendirdik. Ayrıca bu arayışın modern dönemlere giden dinsel bireyselleşme ve dinsel çoğulculuk gibi arkaplanının olduğuna ve bunun medyada daha ileri biçimlerde devam ettirildiğine işaret ettik. Bu yeni kimliğin yani dünyanın yeniden büyülendirilmesinin popüler kültür ve de medya ile taşındığına dikkat çektik. Bu işlevsellikte en önemli rol de mitlere ve paranormal inançlara düşmektedir. İnsanların popüler kültür aracılığı ile süper paranormal güçler kazanma ve hapsolduğu rasyonel demir kafesten kurtulma arzuları arasında ilişki bulunmaktadır. Popüler kültür ayrıca, bireysel hazları hesaba katan seküler ve tüketime dönük özelliklere sahiptir. Kutsal, popüler kültür içinde görünür olmaya başlarken onun bu haz ve eğlenceye dönük ve tüketime odaklı seküler karakterinden de etkilenmektedir. Kapitalist tüketim kültürü ile bu paranormal eğilimlerin iç içe girdikleri, çağımızın küresel iletişim ve tüketim araçlarına çok iyi adapte oldukları görülmektedir.

Anahtar Kelimeler: postmodern yeni dinsel kimlik, paranormal inanç, popüler kültür, dünyanın yeniden büyülü hale gelmesi, mit.

\section{Giriş: Yeni Dönem Yeni Kimlikler}

Bu yazının konusunu postmodern diye adlandırılan görece "yeni" dönemde paranormal inançların yeri, gelişen önemi ve bunun günümüzün manevi-dini dünyasına getirdiği yenilikler oluşturmaktadır. Postmodernle gelen bu yeni dönemin "yeni kimlik"lere yol açtığı, bu kimliğin oluşumunda kutsallıkların da önemli bir rol oynadığı görülmektedir. Özellikle "yeni anlam arayışları" ve "dünyanın yeniden büyülünderilmesi" çerçevesinde oluşan yeni kimliklerin gelişiminde esoterik ve paranormal inanışlar işlevsel olmaktadır.

Günümüzde bir çok açıdan yeni ve farklı bir döneme girildiği ve bunun çeşitli kavramsallaştırmalarla tanımlanmaya çalışıldığ görülmektedir. Bu yeni durum özellikle din alanında kendisini göstermektedir. Gelinen noktada "kutsala dönüş veya kutsalda patlama" gibi bir durumla karşı karşıya olduğumuz artık açıkça görülmektedir. Din "erken modern dönem" de olduğu gibi özel dar bir alanda tutulmanın aksine kamusal alanın her biriminde kendisini ifşa etmeye başlamıştır. Bu sadece kurumsal dinlerde değil mistik, büyüsel ve paranormal alanlarda hatta geleneksel dönemde sir olarak çok dar bir alanı işgal ederken günümüzde postmodern bir 
"fâş" olma durumuyla karşı karşıya olan "esoterik bilgi" de dahi görülmektedir. Özellikle mistik, esoterik ve paranormal inanışların son dönemdeki etkin görünürlüğü ve "paranormalizm" denebilecek tarzda evrensel bir fenomen olarak insanların ilgi alanına girmesi günümüz manevi-dini hayatının pek farkedilemeyen bir aysbergi olarak önümüzde durmaktadır. Esoterik ve paranormal inanç ve uygulamaların postmodern dönemlerdeki bu ilginç yayginlığı gelecek dönemlerde de dinbilimi ve sosyal bilimlerle uğraşanları çokça meşgul edececeğe benzemektedir.

Postmodern kavramını sosyal bilimciler, yaşadığımız dünyada karşılaşılan yeni durumları ifade etmek için kullanmaktadırlar. Günümüz dünyasının önceki dönemlere nazaran birçok köklü yeniliği içinde barındıran bir özelliğe sahip olduğu açıktır. Dolayısıyla bu yeni dönemi kavramsallaştırmada kullanılan "enformasyon toplumu, risk çağı, geç modern çağ gibi" kavramlar yanında "postmodernizm" de yerini almaktadır. Postmodern kavramını modern dönemle ilişkili olarak kullananlar olduğu gibi Lyotard gibi kimi düşünürlerce eski dönemden bir "kopuş"u ifade eder tarzda da kullanılmaktadır. İster eski dönemle ilişkili isterse farklı bir dönemi ifade eder tarzda kullanılsın, klasik modern çağdan kimi açılardan farklı bir döneme girdiğimiz açıkça görülmektedir. Bazı açlardan, örneğin küreselleşme gibi modernliğin radikal biçimleriyle karşılaştığımız gibi Giddens'ın deyişiyle "modernliğin de ötesinde durumlarla"1 da karşılaşabilmekteyiz.

Gerçekten de postmodernin ne olduğunu anlamak için modernlikten gelen özelliklerini hatta onun daha ileri düzeylerini gördüğümüz gibi farklı özelliklerle de karşılaşabilmekteyiz. Modernliğin konumuz açısından "iki yönlü" bir karaktere sahip olduğunu söyleyebiliriz. İlki insana sağladığı güvenli yaşama yönü, ikincisi ise karanlık yön diyebileceğimiz ve eskiye nazaran daha kompleks riskleri insan hayatına sokmasıdır. Modernliğin tıkandığ 1 noktalara ilişkin yorumlar insanlığın yeni bir evreye girip girmediğine dair tartışmaları beslemektedir. Modernliğin zorlandığı durumlara bakıldığında gelinen noktada "büyük modern anlatılara kuşku duyulduğu, aşırı rasyonelleşmenin getirdiği problemlere karşı farkındalıkların arttığı, enformasyon teknolojileri, küreselleşme, kimlik merkezli yeni sosyal hareketlerin doğuşu" gibi modernliği aşan durumların ortaya çıktığı kolaylıkla görülebilir. Postmodern kavramını kullananlar yukarıdaki gelişmeleri modern-

1 Antony Giddens, Modernliğin Sonuçları, Çev.: E. Kuşdil (İstanbul: Ayrıntı Yayınları, 1994), s. 10. 
liğin ileri hali olarak görmek yerine yeni bir dönemin belirtileri olarak görme eğilimindedirler. Onlara göre yukarıda zikredilen belirtiler yanında "öznellik, görecelik, akılcılcı̆̆ tenkit, çok kültürlülük, melezleşme, dinsel ve cemaatsel olana ilgide artış, simülasyonun yani gerçek olamayanın görünür, işler hale gelmesi" gibi kavramları da yeni dönemin belirleyicileri olarak görme eğilindedirler². Sonuçta ister modernliği aşan durumlarla ister modernliğin ötesinde yeni bazı "durum"larla karşılaşalım gelinen noktada yeni bir dönemin içinde olduğumuz kuşku duyulmaz biçimde karşımızda durmaktadır. Siyasetten ekonomiye, kültürden dini hayata kadar birçok alanda bu farklılığı ve "yeni durum"u görmek mümkündür.

Şüphesiz bu yeni durumu anlamak için modernliğin içindeki "felsefi-varoluşsal anlam krizi"ne de işaret etmek gerekir. Modern toplumun ürettiği büyük anlatılara, teorilere duyulan düş kırıklı̆ ve anlam arayışı yanında aşırı rasyonelleşme ve yaygın teknolojileşmenin getirdiği patolojik durum varoluşsal bir anlam arayışını da beraberinde getirmiştir. mevcut sıkıntı ve huzursuzluklara çözüm sunamaması, tatminkâr "teodiseler" oluşturamaması ile yakından alakalıdır. Bunun sonucunda gelişmiş modern toplumlarda kutsala dönüş eğilimi çok net biçimde görülmektedir. Bu eğilimin mistik, paranormal eğilimlerden büyüye, ordan da kurumsal dinlere kadar çok geniş bir skala içinde kendisini gösterdiğini belirtmek gerekir. Kutsala dönüş olgusu modern din sosyolojisinin temel konuları arasında yer almaktadır. Din sosyologları, özellikle altmışlı yıllardan sonra kendisini net biçimde gösteren ki bu olguyu "büyük uyanış", "oryantal dini uyanış", "yeni dinsel bilinçlilik", "dinin yeniden kuruluşu" "büyük çağdaş dinsel kriz" vb. biçimlerde adlandırmışlardır. Bu değerlendirmelere göre, altmışlı yıllardan bu yana gelişmiş toplumlarda dini ve ruhsal temalar doğulu dinler, geleneksel dini öğretiler, mistik ve paranormal inançlar, yeni pagan dini akımlar tarzında çok boyutlu biçimde görünmeye başlamıştır. ${ }^{3}$

Yukarıda zikredilen "yeni arayış" sürecinde başlayan kutsala dönüş eğilimi "yeni tarzlar" yanında eski modern dönemdeki yapısal bazı özellikleri de beraberinde taşımaktadır ki buna kısaca değinmek amacındayız. Postmodern dönemdeki yeni dinsellikleri anlamak için modern dönemde dinin aldığı biçimleri bilmek gereklidir.

2 Dursun Çiçek, Postmodernizmin İslamcılar Üzerindeki Etkileri (Kayseri: Rey Yayınlar1 1997).

3 Bkz. Mustafa Arslan, Paranormalizm ve Din (Malatya: Bilsam Yayınları, 2011). 


\section{Modernliğin “Post"una Bürünmüş 'Postmodern'}

Postmodern dönemin kimi özelliklerinin modern dönemden izler taşıdığı çok açıktır. Bu durum konumuz olan dine yaklaşımda da söz konusudur. Postmodern toplumlarda kutsala dönüşle birlikte ortaya çıkan eğilimlerin ve yeni tarzların oluşumunda klasik modern dönemde dinde görülen değişimlerin de etkisi bulunmaktadır. Bu bölümdeki görüşlerimiz "Paranormalizm ve Din" isimli çalışmamızdaki "Modern toplumda din" başlığı altındaki tespitlere dayandırılacaktır.

Modern toplumla birlikte dinin kamusal anlamda geri plana itildiği söylense de modernliğin dini tamamen dışladığı şeklindeki ön yargı yanlıştır. Modern toplumları tamamıla materyalist, seküler ve din dışı olarak tanımlamak yanıltıcıdır (Bellah, 1981: 288). Modern toplumda din, kamusal hayatta geri planda olsa da varlığını bir şekilde devam ettirmiş ama en önemlisi geleneksel toplumlara nazaran "kendi içinde de farklı değişimler geçirmiştir". Başka bir deyişle modern dönemde büyük çaplı toplumsal değişimler sebebiyle, geleneksel dindeki gerileme, yeni bir kutsallık anlayışına evrilmeyi ve yeni dinsellik biçimlerini beraberinde getirmiştir. Bu durum, bir takım seküler kavramların kutsal işlevler görmesi şeklinde olduğu gibi, paranormal inançların, mistik ve kültsel akımların, yeni dinsel hareketlerin sonradan yaygınlaşması şeklinde de ortaya çıkmıştır. Sonuçta modern toplumsal süreçte kurumsal dinlerin zayıflaması modern insana "yeni kutsallık tarzlarını keşfetmesinin önünü açmıştır".

Modern dönemde dini alanda ortaya çıkan bu değişimlerin iki temel nedene dayandığını söylemek mümkündür. İlki, modernliğin getirdiği (aşırı rasyonelleşme, maneviyattan uzak pozitivist ve maddi yaşam anlayışı gibi) kimi rahatsızlıkların neden olduğu "anlam kaybı" ve "yeniden nükseden maneviyat açlı̆ıı"dır. Diğeri de, modernlikle gelen "bireyselleşme" ve dinlerin kurumsal niteliğinin zayıflamasının doğurduğu "dinsel çoğulculuk"tur. Bu iki temel etken, günümüz toplumlarındaki kutsala dönüş eğilimlerinin gidişatını belirlemede, din alanında görülen yeni dinsel kimliklerin oluşumunda belirleyici konumdadır.

Öncelikle ileri toplumlarda aşırı refah ve rasyonelleşmenin getirdiği bir anlam kaybından sıklıkla bahsedilmektedir. Modernleşmenin getirdiği "hızlı değişim süreci", toplumun teknolojik ağırlıklı mekanik işleyişi, aşırı rasyonelleşme ve bireyselleşme ile birlikte bir "maneviyat boşluğu" doğurmuş, bu boşluk da toplumsal anlamda genişledikçe farklı ve yeni bir takım inanç hareketlerine zemin oluş- 
turmuştur. Özellikle küreselleşme ile bu eğilimler daha da yaygınlaşmakta, farklı ruhsallıklar türemektedir. Çünkü küreselleşme, kesinlikle "geleneksel ve cemaatsel olanı" teşvik etmektedir. ${ }^{4}$ Aşırı rasyonel bir dünyada yetişen ve hayatı seküler bir tarzda yorumlayan bireyler, dini ve mistik eğilimlere daha fazla ilgi göstermektedirler. Din sosyologu Berger'e göre ${ }^{5}$, sekülerleşme sürecinde aşırı rasyonelleşme ile "sosyo-dini süreçler açısından modern insan için yeni bir durum ortaya çıkmıştır. Sadece devlet ve ekonomi gibi büyük kurumlar için değil, günlük hayatın gelişi güzel alışkanlıkları için dahi bir anlamsızlık sorunu baş göstermiştir."

Günümüzde modernliğin krizi konusu, günümüzde "güven, risk toplumu ve sosyal kaygı" gibi kavramlar etrafında sıklıkla tartışılmaktadır. Özellikle Beck (1992) ve Giddens'ın (1994) ileri sürdüğü bu argümana göre, modern toplum artık bir 'Risk toplumu'dur. Modern süreçte, kurumsal dinlerin de zayıflaması ile bu sorunu çözmede yeni dini hareketlerin ve paranormal inançların önü daha çok açlmıştır. Bu durum, modernliğin mevcut sıkıntı ve huzursuzluklara çözüm sunamaması ile alakalıdır. Modern toplumlardaki hızlı toplumsal değişimin doğurduğu bir takım sorunların güvenlik sorunu ve yaygınlaşan bir takım risk ve kaygılarla ilişkili olduğunu belirtmek gereklidir. Yaygınlaşan risk ve kaygılar ile anlam arayışları mistik ve paranormal inançlara eğilimi gittikçe artırmaktadır.

Günümüzde kutsala yönelişle alakalı diğer bir husus modernliğin "bireyi" ön plana çıarmasıdır. Modern toplumda din konusunu irdeleyen din sosyologların genelinde ortak olan nokta "bireyselleşme", "öznelleşme" ve bunun sonucu olarak modern dini yaşamda görülmeye başlayan "dini çoğulculuğa vurgu" olarak kendisini göstermektedir. Modernlikle ilgili tanımlamalarda en önde gelen kavram "birey olmak"tır. Bu durum şüphesiz dini hayat açısından da böyledir. Başta Weber olmak üzere, Berger, Luckman, Wilson, Bellah gibi modern dönem din sosyologlarının çözümlemelerinin merkezinde "bireyselleşme" vurgusu ve bunun dini hayatta doğurduğu sonuçlar yer almaktadır. Genel olarak analizlerindeki bireyselleşme ve öznelleşme vurgusu, geleneksel dinsel kurumlara mesafeli olmayı ve bireyi daha önemseyen bir dinsel biçimi ifade etmektedir.

4 Roland Robertson, "Küreselleşme ve Geleneksel Dinin Geleceği”, Dini Araştırmalar (Çev.: İ. Çapçıŏlu). 6 (17), 2003, s. 354.

5 Peter Berger, Dinin Sosyal Gerçekliği, Çev.: A. Coşkun (İstanbul: İnsan Yayınları, 1993), s. 184. 
Modern toplumsal süreçte dinsel kurumlar, toplumsal hayatın kuşatıcı sembollerini tekelinde tutma imtiyazından mahrum kalmışlardır. Bu süreçte din, eskisi gibi tekelci konumda değildir ve bireyin önünde dinsel çeşitlilik arzı endam etmekte ve birey, oldukça "farklı" dinsel görüşlerle karşı karşıya kalabilmektedir. Dini çoğulculuk sebebiyle de, modern birey için artık din, bir zamanlar geleneksel dinsel kurumlar tarafından kendisine sunulduğu gibi şüphe götürmez nesnel bir geçeklik değil, barındırdığ 1 çeşitlilik içerisinden "seçim yapılabilen bir olgu" haline dönüşmüştür. Farklı dinsel organizasyonlar, taraftar toplamak için "rekabet etmek" zorundadırlar ve bu rekabet, üyelerin eskisi gibi bir sadakat tarzına sahip olmadığı anlamına da gelmektedir. Bu sebeple modern toplumda, dinsel görüşlerin piyasaya sunulması ve potansiyel alıcılara iletilmesi önemlidir. Bu da rekabet ortamını yansıtacak şekilde organize olmayı gerektirmektedir. Dinsellikte rekabetin ve pazar mantığının işlemesi, "sunulan mesajın orijinal ya da kitabi oluşundan ziyade, bireyin mesajı kabul edip etmeyeceğini" yani "bireyi/tüketiciyi" ön plana çıkarmaktadır. Böylece, yeni dinsel grupların bireye, "geleneksel inançlardan farklı niteliklere sahip bir takım inanışları kabul ettirme" imkânı doğmaktadır. Sonuç olarak bu sosyo-dini durum modern toplumda -eski kurumsal dinlerden farkl1- yeni dini ve mistik tezahürlerin oluşumuna neden olmuştur. Bu ve benzeri sebepler, anlam ve kimlik arayışındaki insanın önüne kurumsal dinlere ve rasyonaliteye muhalif inanışları çıkarmıştır. İşte paranormal inançlar bu bağlamda postmodern insanın anlam dünyasında eskisine oranla daha fazla yer etmeye başlamıştır.

Postmodernizmin önemli özelliklerinden birisinin "dine ve geleneklere dönüş" olduğuna yukarıda değinilmişti. Modern dönemde dinde görülen bu değişimler ile postmodern dönemdeki bu dinsel ve tinsel canlanmayı bir arada değerlendirmek, postmodern dönemdeki Yeniçağ dinselliğini ve paranormal inançların yaygınlaşmasını daha iyi anlamamızı sağlayacaktır. Postmodern dönemde anlam arayışı ve aşırı rasyonaliteye antipati duyma ile birlikte dinler yanında pre-modern dönemdeki geleneklere dolayısıyla paranormal inanışlara ilgide artış olmuştur. Postmodernite ile pozitivist, rasyonalist gelenek yıkılmıştır ve bu durum "geleneksel, cemaatsel ve tinsel canlanma" ile desteklenmektedir. ${ }^{6}$

Geç modern dönemde din ve maneviyat alanında görülen bu yeni durumlar postmodern dönemde yeni dinsel kimliklerin ve yeni kutsallık tarzlarının da önünü açtı. Özellikle postmodernizmin “her

6 Çiçek, Postmodernizmin İslamcllar Üzerindeki Etkileri, s. 83. 
şey gider" mantığ ile pozitivist ve rasyonalist geleneğe karşı kadim geleneklerdeki farklı tinsel öğeler postmodern bireyin anlam aray1şının hizmetine sokulmuş oldu.

\section{Modernin Sonrası Normalin Ötesi}

Buraya kadar yazılanlardan anlaşılacağı üzere modern dönemde, geleneksel dinlerden "farklı kutsallıklara" yönelişin "yolu" açılmış olmaktadır. Bu durum postmodern dönemdeki arayışlar arasında da kolayca karşılık bulmuş aynı zamanda kutsala dönük anlam arayışlarının da biçim ve içeriğini belirlemiştir. Bu bağlamda karşımıza paranormal inançlar çıkmaktadır. İlginçtir, "paranormalizm" ve "postmodernizm" kavramlarının her ikisi de "ötesi" anlamına gelen ön eke sahiptir. İkisi de modernliğin pozitivist ve aşırı rasyonel karakterinden şikâyetçidir. İkisi de insanın anlam arayışını fiziksel doğa çerçevesinde aramaya itiraz etmektedirler. Modernliğin insanı getirdiği bu anlam krizinden kurtulmanın yolunu her ikisi de var olandan "öte" de, başka "varoluş durumlarında" arama taraftarıdırlar. Peki, bu bağlamda postmodern dönemde karşımıza çıkan "paranormalizm" ya da paranormal inançlar nedir?

Paranormal normal hayatın, fiziksel gerçekliğin dışında, ötesinde olanı ifade etmektedir. Sözlükte paranormal, "rutin, bilinen ve tanınan kanunlar ve doğal güçlerin ötesinde olan ve bunlarla açılanamayan" şeklinde tanımlanmaktadır. Paranormal iddialar, insan kapasitesinin dışında olan ve sebep sonuç açılamasıyla uyumsuzluk gösteren güçler, fikirler ve olgular için kullanılmaktadır. Paranormal inançların teorik ve operasyonel olmak üzere iki farklı tanımı yapılsa $\mathrm{da}^{7}$ biz burada teorik tanıma işaret edeceğiz. Buna göre paranormal, "mevcut bilimin açıklayıcı gücünü görünüşte aşan, bilinmeyen veya gizli nedenlerden doğan şey" ya da "kurulu bilimin sınırlarının dışına çıktığı ileri sürülen açılamalara güvenme" şeklinde tanımlanabilir.

Paranormal inançların en önemli özelliği senkretik karakterde oluşudur. Birbirinden çok farklı inanç ve uygulamayı bünyesinde taşımaktadır. Şeytan, melek, cin, öte dünya gibi dini içeriğe sahip mekan ve varlıklardan hayalet, UFO gibi fantastik varlıklara, büyüsel ve ruhsal güçlerden medyumluk, psişik gibi uzmanlıklara, batıl inançlardan zihin ve ruhsal bazı güçlerle nesneleri hareket ettirmeye, uzaktan zihinsel telkin (hipnoz) yoluyla etkileme, trans halinde kehanette bulunma gibi vakalara kadar bir çok fenomen

7 Bkz. Mustafa Arslan, "Paranormal İnanç Ölçeğinin Türkçe Versiyonunun Geliştirilmesi: Geçerlik ve Güvenirlik Çalışması", İnönü Üniversitesi, İlahiyat Fakültesi Dergisi, 1 (2), 2010, ss. 23-40. 
paranormal inanç sistemini meydana getirmektedir. Bu çeşitlilik sebebi ile paranormal inanç sistemi, "çok boyutlu" bir nitelikte karşımıza çıkmaktadır.

Paranormal inançlar çok yönlü bir mahiyete sahiptir. Paranormal inançların özelliği senkretik / terkibi bir özelliğe sahip olmasıdır. Bu anlamda paranormal inançlar çok farklı kültür ve dinden ögeyi içerisinde barındırır. Pagan kültürlerden evrensel dinlere kadar çok farklı yelpazede inanışlar bu çatı altında kendisine yer bulmaktadır. Mitler, büyü, burç ve astroloji, medyumluk, fal, kehanet, telekinezi, süper varlıklar, telepati, dejavu, astral seyahat, psişik, gezegenlerde hayat veya olağandışı yaşam formları, batıl inançlar gibi çok farklı inanç ve uygulama paranormalizm çatısı altında var olmaktadır. Paranormal inançlar bir taraftan din ile ve hatta pagan kültür ve mitlerle diğer taraftan ise bilimsel söylem ile ilişki halinde olmaktadır. Bu farklı ve zıt kutuplardan aldığı unsurları kendi potası içerisinde eritebilmektedir. Burada alınan temel kıstas ise "normal-fizik ötesi" olmaktır. Fiziksel kuralların dışında farklı bir mantaliteye dayanan (yani paranormal biçimde işleyen) bir dünya görüşüne sahiptir ve sistem bu temel ölçütü merkeze alarak farklı unsurları dairesi içerinde absorbe etmektedir.

Paranormal inançlar "din" ile çok yakın ilişki içerisinde olmuştur. Ancak bazen dini olanla uyumlu olduğu gibi bazen da ona zit inançları içerisinde barındırabilmektedir. Örneğin öte dünyanın varlığı, ruhun ölmezliği, insanüstü varlıklar vb. daha birçok konuda dinden beslenmektedir. Bazen büyüsel, efsanevi, mistik kimi inanç ve uygulamaları dinle iç içe biçimde sunabilmektedir (kerametler, dini mistik uygulamalar vb.). Ancak diğer taraftan sert batıl inançlar, kara büyü, fal, kehanet gibi dine zıt olan inanışları da içerisinde barındırabilmektedir.

Paranormal inançlar ilginç biçimde "bilimsel söylemi" de kullanmaktadır. Modern en son bilimsel keşif ve ürünleri kendi anlam dünyası içinde yorumlamaktadır. Eski mit ve efsaneleri günümüz uzay ve astroloji biliminin verileri ışığında terkib ederek insanın normal ötesi ufkuna hitap etmektedir. Din ve bilim birlikte paranormalizmin anlam evreninde birleşerek insanın fiziksel dünyanın s1nırları dışındaki anlam arayışına hizmet etmektedir. Paranormalizm, modernizmin aşırı rasyonalizm ve bilimcilikle bu dünyaya hapsettiği insanı din ve mitler vasıtasıyla farklı aşkın alanlarda seyahat ettirebilmektedir. Bilimsel veriler vasitasiyla da demode bir yöntem olmayıp yeni olduğunu, "modern" zihinlerin aşkın arayışında eskiden güncele uzanan hareketli ve diyalektik bir 
yapıya sahip olduğunu ima etmektedir. Bu şekilde "modern" insanın yeni anlam arayışına bir cevap olabilmektedir. Burada tekrar paranormalizmin bu çok çeşitli yapısı ile postmodernizmin "anything goes / her şey gider" mantığının birbirini tamamladığını da hatırlamak gerekir.

Paranormal inanç konusu aslında bu nedenlerle, sosyal bilimlerin daha üst perdeden tartıştığı kadim bir konu olan "büyü, bilim ve din ilişkisi" çerçevesinde ele alınmalıdır. Paranormal inançlar da aslında tarih boyunca bu üç alanın karışımından mürekkep biçimde karşımıza çıkmıştır. Bazen mistik, büyüsel bir konu dinsel içerikle (keramet, vb.), bazen de bilimsel söylem içinde (Ufoloji, astroloji, sayntoloji, yabancıların dünyayı ziyareti, yıldızlararası iletişim vb.) ele alınabilmektedir. İlkel veya geleneksel toplumlarda büyüseldinsel inanışların mevcudiyeti konusunda çokça değerlendirme yapilırken modern toplumlarda paranormal inançların mevcudiyetine eğilen çalışmalar yeterli değildir. Ancak yapılan mevcut çalışmalardan anlaşılan geç ya da post-modern dönemde paranormal inançlara ilgide bir artış olduğudur. ${ }^{8}$

\section{Kesişen Roller Kesişen Kimlikler: 'Büyüsü Bozulan' Dünyayı Yeniden ‘Büyülemek'}

Paranormal inançlar aşırı rasyonalist ve tüketimden sıkılmış ve anlam arayışı içinde olan modern insanın bu arayışına karşılık gelmektedir. Burada "paranormal inançların anlam arayışı gibi yüce bir anlamla nasıl yan yana geldiği" sorusu akla gelebilir. Şu unutulmamalıdır ki postmodern dönemde meta anlatılara da büyük eleştiriler yapılmakta ve onlardan da uzak durulmaktadır. Dolayısıyla hem akılcı ve maddeci düşüncelerden daralan, bıkan hem de meta anlatıların perspektifinden sıyrılmaya çalışan arayışlar bir meta anlatı özelliği göstermeyen ama rasyonalist bir yapısı da olmayan paranormalizme yakın durmaktadırlar.

Burada Weber'in modernliği tanımlarken kullandığı "dünyanın büyüden arındırılması" kavramını hatırlamak gerekir. Weber'e göre modern toplumların en belirleyici nitelikleri "sekülarizasyon, rasyonalizasyon, entelektüelizasyon ve hepsinin üzerinde "dünyanın büyüsünün bozulması (disenchantment)" kavramlarıdır. Weber özellikle rasyonalizasyon, entelektüelizasyon kavramlarını, dini düşüncede artan sistematizasyonu ve aklileşmesi, dinde ayinsel ve büyüsel öğelerin giderek azalmasının bir ifadesi olarak ele alır. Bütün bu kavramlar Weber'e göre modern zamanların "kader"ini belirler.

$8 \quad$ Bkz. Arslan, Paranormalizm ve Din. 
Ancak Weber zamanı ve özellikle gelecek için karamsardır. Bürokratik rasyonel geleneği "demir kafes" olarak niteler, "Bizi bekleyen bir kutup gecesinin buzlu karanlığı ve zorluklarıdır" ve "Gelecekteki yaz mevsiminin açacak çiçekleri yok" sözleri onun modern toplumlarla ilgili karamsarlığını çok güzel yansıtır. ${ }^{9}$ Weber'in modernliği eleştiren bu ve benzeri yorumları, onun fikir ve kavramlarının postmodern düşünürlerce ve hatta paranormal inançları merkezlerine yerleştiren Yeniçağcllar tarafından halen kullanılmaktadır. ${ }^{10}$

Paranormal inanç ve uygulamaları hareketlerinin merkezine alan Yeni Çağ gibi Postmodern Yeni dinsel akımlar, kendi hareketlerini açıklarken Weber'in modern, rasyonel sisteme dönük eleştirilerini ve umutsuzluklarını kullanırlar. Yine yeni dinsel akımların sosyolojik açıklamasını yapan sosyal bilimcilerin Weber'in yukarıda değindiğimiz kavram ve yaklaşımlarını zaman zaman kullandıkları görülür. Örneğin Yeniçağcllar, modern toplumunun ileri teknolojiye sahip kültürünün, maddi bir rahatlık sağlasa da manevi huzuru sağlamadığı iddiasını ileri sürerler ve "anlam krizi"ne çokça atıfta bulunurlar. Onlara göre, ruhsal ve paranormal konular önümüzdeki günlerde insanlık tarihinin en önemli gerçekliği olarak ön plana çıkacaktır. Ayrıca Yeniçağcılar, anlam krizinin kitle bilincinde bir "paradigma kayması" için ivme teşkil edeceğine vurgu yapmaktadırlar. ${ }^{11}$ Yeniçağcılar kendilerini modern toplumların "demir kafes"ten çıkmalarına bir cevap, "eski fikir ve ideallerin büyük yeniden doğuşu" ve "büyüsü bozulan dünyanın büyüsünü yeniden kazandırma" olarak adlandırmaktadırlar. ${ }^{12}$ Onlara göre nasıl "kapitalizmin ruhu" nu rasyonel teolojiye sahip "Protestan etik" oluşturmuşsa "postmodernizmin ruhu"nu da paranormal mantaliteye dayanan "Yeniçağ etiği" oluşturacaktır.

Weber'e göre modern dönemde Hiristiyanlık, bilim, teknoloji ve kapitalizmin, yaygin biçimde rasyonelleşen bir dünya kurmaya hizmet etmişlerdir. Modernlik, mitlerden, büyüden arındırılmış bir

9 Max Weber, Sosyoloji Yazıları, Ed.: H.H. Gerth ve C.W. Mills; Çev.: T. Parla (İstanbul: İletişim Yayınları, 1996); Max Weber, The Protestant Ethic and the Spirit of Capitalism (New York: Charles Scribner's Son, 1976).

10 Bkz. Patrick Sherry, Disenchantment, Re-enchantment, and Enchantment, Modern Theology 25: 3, 2009.

11 Sonja St. Amant, Faith by Demonstration: The Connection Between The History of Paranormal Phenomena and a New Age Spirituality, State University of New York, College of Arts \& Science, Department of History (Basılmamış Doktora Tezi), 2003, s. 12.

12 Bkz. Amant, Faith by Demonstration, ss. 251-2. 
kültür yaratmıştır. Bu da geleneksel toplumlara nazaran aşırı rasyonel bir toplumu doğurmuş, büyüsü bozulan bu dünya anlam krizine sahip olmuş yeni anlam arayışlarına da sahne olmuştur. Şüphesiz bu arayış irrasyonel tarzda olmakta ve büyüsü bozulan dünyanın yeniden büyülendirilmesi süreci söz konusu olmaktadır. Postmodern toplumlarda belirginleşmeye başlayan paranormal, mistik ve büyüsel olana, ilerlemeci anlayış yerine bütüncül tarih tasavvuruna, doğu dinlerine ve gizemciliğe yönelik eğilimler, "büyüsü bozulan" bir dünyanın yeniden "büyülü kılınması", zevkli ve eğlenceli hale getirilmesi olarak da değerlendirilebilir mi sorusunu akla getirmektedir. Örneğin postmodern bir sosyolog olarak tanınan Z. Bauman ${ }^{13}$ postmodernizmi, büyüsü bozulan dünyanın "yeniden büyülü hale getirilmesi" olarak nitelemektedir. Yine Ritzer ${ }^{14}$ de geç modern dönemdeki tüketim kültürünün geldiği noktayı incelemede aynı kavramsallaştırmayı kullanmaktadır. Ona göre büyüsü bozulan modern dünyada kimi fanteziler ve simülasyonlar üretilerek tüketim cezbedici bir niteliğe sokulmakta; "tüketim katedralleri" adını verdiği yeni tüketim araçları ile yaşanan an "büyülü" hale getirilmektedir. Günümüzde bazı postmodern teorisyenler bu teorinin temellendirilmesinde Weber'e dönmeye başlamışlardır. Weber' in birçok yaklaşımı yanında yukarıdaki yaklaşımları -bir anlamda modernliğin içinden cevaplar olsa da - postmodern teori için anlamlı da görülmektedir.

Postmodern insanın anlam arayışında ve büyü bozumuna uğrayan dünyanın yeniden büyüsünün kazandırılmasında paranormal inançlar işlevsel olmaktadır. Ancak bu işlevselliğin anlaşılması için günümüz toplumlarının yeni bir özelliğine dikkat çekmek gereklidir. O da günümüzün aynı zamanda bir "Enformasyon toplumu" olduğu gerçeğidir. Dolayısıyla günümüz insanının anlam veya başka bir deyişle "postmodern kimlik arayışı" nda "medya" başat rolü oynamaktadır.

Enformasyon toplumu ile yukarıda değinilen bireysel kimlik arama uğraşısı ve dini çoğulculuk daha uç noktalara varmaktadır. Bu süreçte bireysel dinselliğin gelişmesi ve "popüler kültür alanının genişlemesi" durumu ortaya çıkmaktadır. Dolayısıyla bu süreçte din, modern toplumun geçirdiği toplumsal süreçler vasıtasıyla oluştuğu yeni ve farklı durum yanında (post)modern durumun en etkin

13 Zygmunt Bauman, Postmodern Etik, Çev.: A. Türker (İstanbul: Ayrıntı Yayınları, 1988) s. 46.

14 George Ritzer, Büyüsü Bozulmuş Dünyayı Büyülemek, Çev.: Ş. S. Kaya (İstanbul: Ayrıntı Yayınları, 2000). 
mekânı olarak medyadaki görünümleri açısından değerlendirilmelidir. Çünkü günümüzde iletişim-medya alanında "kutsal"ın "yeniden üretilir ve de tüketilir hale geldiğini" görüyoruz. Bu durum postmodern kimlik süreci ile ve bu sürecin önemli bir ayağı olan paranormal inançlarla yakından ilişkilidir. Dinin ve kutsalın yeniden yaygınlaşmasına paralel olarak postmodern toplumda yeni kutsallık tarzları oluşmakta, paranormal inançlar da buna paralel olarak medya vasıtasıyla yaygınlaşmaktadır.

Belirtildiği gibi "enformasyon" günümüz toplumlarını belirleyen temel özelliklerden en önemlisidir. Sanayi toplumundan Enformasyon toplumuna geçiş, iktisadi faktörlerin yerine "enformasyonun" kullanıldığı, fabrika yerine yüksek teknolojilerin uygulanmasına bağlı bir geçiştir. Bu aynı zamanda "yazı merkezli" dünyadan "imaj" merkezli dünyaya (TV, reklamlar, filmler, internet) bir geçişi de ifade eder. Bu toplumdaki insan tipi ise, "bilgi ve enformasyon bombardımanı altında kalan, çevresindeki sonsuz uyaranlara maruz kalan" insan tipidir. Buna "manipülatif insan tipi" de diyebiliriz. Bu durum şüphesiz dini kültür alanında da söz konusu olmaktadır.

İnsan hayatında çok önemli olan toplumsallaşma sürecinin en önemli iki gücü olan "din ve kitle iletişim araçları" topluma şekil vermek, değer yaratmak ve benimsetmek, düzen kurmak ve kontrol etmek gibi işlevlere sahiptir. Sanayi toplumu öncesi iletişim araç ve tekniklerinin gelişmediği dönemlerde dini kurumların toplumsallaştırıcı gücü çok başat idi. Ancak önce matbaa daha sonra kitle iletişim araçlarındaki gelişmeler, "dini kurumlar"ın elindeki toplumsallaştırma işlevini almış ve/ya paylaşmış görünmektedir. Dini bilgi ve düşünce kanallarındaki akışta "değişiklik" olmuştur. Yeni dönemde bilginin akışı, eskiden olduğu gibi dini kurumlar aracılığı ile değil, "medya aracılığı ile ve yeni sembolik, kültürel merkez ve şebekelerden sağlanmaya başlamıştır". Medyadaki çeşitli tartışma programları, belgeseller, filmler, diziler ve hatta reklamlarda dinsel sembollere göndermeler yapılmakta, yeni semboller geliştirilmekte, doğaüstü varlıklar ve güçleri ile ilgili betimlemeler yapılmakta, duygulara hitap eden dramatik bir ortam yaratılmakta ve din her seferinde yeni bir içerik ile malzeme yapılmaktadır. Burada asıl önemli nokta, "medyanın uhrevi âlemi kutsallık adına okuyup kitlenin hizmetine sunması" ile başlamaktadır. Paranormal inançlar burada devreye girmekte, özellikle dinle ortak biçimde işlevsel olmaktadır. 
Postmodern toplumun kimlik arayışında paranormal inançların nasıl işlevselleştiğine diğer bir örnek de medyanın "mitik karakteristiğe" sahip oluşudur. Medya olay, fikir ve inançları popüler bir söylem içine yerleştirir. Medya için yazılı olmaktan çok "sözlü kültüre" benzer, "mitik biçimleme" dili önemlidir. Günümüz "medya çağı" Ong'un belirttiği gibi aynı zamanda "ikinci sözlü kültür çă̆ı" ve "mitin keşif çağı"dır. Ong15, iletişim araçlarını birer "sözlü kültür" formu biçiminde düşünebileceğimizi, enformasyon teknolojilerindeki yaygınlaşmanın bizi "ikincil sözlü kültür çağı"na sokmuş bulunduğunu vurgulamaktadır ve bu görüşünde yalnız da değildir. Sözlü kültüre dönüş demek, Sözen'e göre, 16 "vasıtalar değişmiş olsa da aslında insana eğilmek ve kaybedenler açısından kutsalı aramak" demektir. Dolayısıyla yazılı kültür sonrasındaki bu "ikinci sözlü kültür çă̆ı", modern toplumun kaybettiği modern öncesi kaynaklarının yeniden keşfini ve kutsala ve dolayısıyla "mit"e dönüşün bir ifadesi olmaktadır.

Mit ve mitik yaklaşım günümüzde popüler kültür aracılığ ile yaygınlaşmakta, mitik imgelere medyada çokça yer verilmektedir. Bu mitik imgelerin içeriğine bakıldığında çoğunlukla paranormal temalar olduğu görülür. Pre-modern dönemlerin büyülü dünyasına dönüş mitik imgelerle paranormal temaların anlam evrenine dönüşten başka bir anlama gelmemektedir. Özellikle sinema ve TV filmlerinde mitik ve paranormal temalar çokça kullanılmaktadır. Mit de TV ve sinema filmleri de insani hakikatlerin taşıyıcısıdır. Bu ortaklık sadece mesajı taşımada değil "mesajı çok çeşitli kültürlere kolaylıkla ve bir defasında taşıma kabiliyeti" nde gizlidir.

Ancak burada değinilmesi gereken bir husus vardır. Her ne kadar mitler köken olarak kutsallık orijinine bağlı olsa da medyadaki kullanımlarında "ikili bir durum" olduğu dikkat çekmektedir. "Dinsel niteliğinden soyutlanıp seküler forma büründürülen mitler" ile bu "kutsallık durumunu devam ettiren mitler" şeklinde "iki farklı mitsel ele alış tarzı" ile karşı karşıya olduğumuzu söylemek yanlış olmaz. Bu da medyanın "ikili karakteri" ni göstermesi açısından önemlidir. Bu ikinci özelliği ile medyada özellikle "mite dönüşle kutsala bir dönüş yaşandığı" söylenebilir. Mitin, büyünün ve paranormalin keşfi ile karşı karşıyayız adeta. Bu da medya dünyasında daha net biçimde görülmektedir. Medyada mit, büyü ve paranormalin yaşamaya devam ettiği unsurları ve deneyim şekillerini çok açık biçimde görmekteyiz. Medya olayları, fikirleri popüler bir

15 Bkz. Walter J. Ong, Sözlü ve Yazılı Kültür, Çev.: S. P. Banon (İstanbul: Metis Yayinlar1, 1995).

16 Bkz. Edibe Sözen, Medyatik Hafıza (İstanbul: Timaş Yayınları, 1997). 
söylem içine yerleştirmekte, mitsel ve büyüsel biçimleme ile farklı bir kutsallı̆̆ bizlere temaşa ettirmektedir. Medya bir popüler kültür alanı olarak temelde seküler bir alandır. Ancak sözlü kültür ve simgesellik özelliği, mitik dile sahip oluşu medyanın yeni kutsallıklar üretmesine ve bunu (post)modern bir bağlamda yapmasına imkân vermektedir. Medya bu anlamda yeni "seküler kutsallıkların" merkezi olmaktadır. Özellikle kutsal, paranormal temaları eğlence kültürü içinde yansıtmaktadır. Medyatik seküler dil ile mitik ve paranormal temalar kurgusal olarak iç içe bir görünüm arz etmektedir. Bu temalar, bir taraftan bireysel ilgi ve hazlara dönük, diğer taraftan ise seküler, akli olanla mücadele ve postmodern kimlik arayışı çerçevesinde ortaya çıkmaktadırlar. Dünyada etkin bir film endüstrisi olarak Hollywood dizi ve film sektöründe mitsel ve dinsel imgelerin çokça yer aldığını biliyoruz. Harry Potter, The Exorcist, İşaretler, Matrix, Paranormal activity vb. daha sayısız birçok ünlü filmde mitsel ve büyüsel imgeler çokça işlenmektedir. Ancak bunlar bir eğlence ve haz kültürü içinde ve seküler tarzda verilmektedir.

Paranormal inanç ve uygulamalar medyadaki kutsal üretimine ve postmodern yeni dinsel kimlik arayışına güzel bir örnek olmaktadır. Günümüzde popüler kültürde paranormal, mistik inanış ve uygulamalara, ruhçu eğilimlere, fal ve astrolojiye, hayaletlere bir ilgi söz konusudur. Araştırmalar bu eğilimlerin daha çok medya tarafından belirlendiği şeklindedir. Eğlence ve turizm sektöründe de ayrıca görülmektedir. Paranormal olgular, kurgusal olsa da sırf eğlence olarak nitelenemez. İnsanların ilgi ve eğilimleri de söz konusu edilmelidir. İnsanların ilgi ve eğilimleri ile medyanın etkisi birleşerek "seküler kutsal" ürünler ortaya çıkmaktadır. Bir taraftan kurgusal ve bireysel ilgi ve hazlara dönük, diğer taraftan ise seküler akli olanla mücadele, dini ve varoluşsal temalara ilgi çerçevesinde ortaya çıkmaktadırlar. Burada "Medyatik dil ile dinsel temalar" kurgusal olarak iç içe bir görünüm arz ederler. Burada The Exorcist filmi örnek olarak verilebilir. Başına olağanüstü şeyler gelen Küçük kızın annesi ateisttir. Onu tedavi eden hem bilim adami hem de rahip olan kişi sayesinde anne sonunda "inanç gerçeği" ile karşı karşıya gelir. The Exorcist of Emily Rose da da durum aynıdır: "Küçük kıza paranormal uygulama yapmakla suçlanan Rahip" ve "küçük kızı savunan ateist bayan avukat". Avukat da sonunda inanç gerçeği ile yüzleşir. Küçük kız Hristiyan müminlere örnek bir kişi olarak sunulur. Bilim-din çelişkisi paranormal bir olay örgüsü etrafında dinin lehine çözülmeye çalışılır. Omen filminde de durum aynıdır yani paranormal olay örgüsü etrafında dinsel mesajlar verme durumu söz konusudur. "Matrix"te ise paranormal-mistik temaların dini ve fel- 
sefi içeriklerle iç içe işlendiğini görürüz. Harry Potter'da yoğun paranormal ve büyüsel temalar eğlence tarzda verilmektedir. The Lord of the Rings'de olağandişı birçok olay büyüsel ve fantastik bir kurgu içinde anlatılır. Signs, Alien, Ghost, The Sixth sense, Dragonfly, X Files, vb. bir çok dizi ve film için de durum aynıdır.

Batıda işlenen bu tarz film ve dizilerden örnekle ülkemizde de özellikle iki binli yıllardan sonra benzer temalı yerli filmlere rastlamaktayız. Büyü, Dabbe, Araf, Semum, Gen, Musallat, Siccin, Şeytan-ı racim, Küçük kıyamet, Üç harfliler, Azazil, Ifrit, Zifir, Ammar, Azem, Gulyabani $v b$. yerli filmlerde paranormal temalar çokça işlenmekte ve bu tarz filmlerin sayısı hızla artmaktadır. Yanı sıra Sırlar dünyası, Kalp gözü, Str kapısl, Strlarm efendisi, Sihirli annem, Tatl cadı, Selena vb." yerli dizilerde mitik, dinsel ve paranormal konuların işlendiğini, bu tarz dizilere çok önem verildiğini görmekteyiz. Bu dizilerin yaygınlığı, bunların çok izlenmesiyle doğru orantılı olmalıdır.

\section{Sonuç}

Günümüzde özellikle popüler kültürde paranormal inanç ve uygulamalara ilgide bir artış söz konusu olduğu açıça görülmektedir. Yukarıda belirtildiği gibi son dönemde yaygınlık gösteren paranormal inanç ve uygulamalar postmodern dönemdeki "yeni kimlik" arayışlarına denk gelmektedir. Postmodern dönemde görülen bu yeni kimlikler özellikle popüler kültürde temsil edilmektedir. Biz bu yazıda postmodern dönemle gelen yeni kimlikleri "dünyanın yeniden büyülendirilmesi" kavramı ile ilişkilendirdik. Ayrıca bu arayışın -özellikle dinsel niteliğinin- modern dönemlere giden bireyselleşme ve dinsel çoğulculuk gibi arka planının olduğuna ve bunun medyada daha ileri biçimlerde devam ettirildiğine işaret ettik. Aslına bakılırsa popüler kültür ve de medya, bu yeni (postmodern) kimliği yani dünyanın yeniden büyülendirilmesi işlevini yerine getirmektedir. Yeni dini hareketler dahi propaganda alanında medyayı kullanmaktadır. Bu işlevsellikte en önemli rol de mitlere ve paranormal inançlara düşmektedir. Popüler kültürün imaj yönlü, yazıya mesafeli sözlü niteliği ile paranormal ve mitik söylem arasında ortak yönler mevcuttur. İnsanların popüler kültür aracılığı ('medya'nın aracı anlamına geldiğini burada hatırlamak yerinde olur) ile süper paranormal güçler kazanma veya hapsolduğu rasyonel demir kafesten kurtulma arzuları arasında ilişki bulunmaktadır.

Ancak paranormal inanç ve uygulamalar, popüler kültür alanında kimliksel işlev görürken popüler kültürün seküler karakterinden de olumsuz biçimde etkilenmektedir. Popüler kültür, karşıdakinin bireysel haz ve isteklerini de hesaba katan seküler ve 
tüketime dönük özelliklere sahiptir. Kutsal, popüler kültür/medya içinde görünür olmaya başlarken onun bu haz ve eğlenceye dönük ve tüketime odaklı seküler karakterinden de etkilenmektedir. Eliade'ı çağrıştırır biçimde "zıtların birliği" yani "kutsal ile seküler" bir arada popüler kültür alanında söz konusu olmaktadır. Eliade'ın meşhur din teorisindeki zıtların birliği tezi postmodern bağlamda sanki yeniden gerçekleşmektedir. Popüler kültür alanı içinde "seküler ama kutsal" yönü olan örnekler söz konusu olmaktadır.

Bu konu ile alakalı diğer husus genelde kutsal, özelde paranormalin tüketim metasına dönüştürülmesidir. Kapitalist tüketim kültürü ile bu ruhsal eğilimlerin iç içe girdikleri, çağımızın küresel iletişim ve tüketim araçlarına çok iyi adapte oldukları görülmektedir. Yine, burada ruhsal tatmin yanında yeni bir tüketim mantığı, "kutsalı metalaştıran bir mekanizma" söz konusudur. Kutsal karşıtı katı seküler anlayışın bırakılarak yeni bir yaklaşımın mevcut olduğu anlaşılmaktadır. Bu, yeni bir paradigmadır ve "kutsalın postmodern seküler süreçlere adaptasyonu" şeklinde de anlaşılabilir. Bu süreçte en gizli esoterik konular dahi popüler kültürün içinde fâş edilmekte, "sırrın metalaşması" denilen bir olgu ile karşı karşıya gelinmektedir. Geleneksel dönemde gizli olan bazı esoterik, mitik öğretilerin medyada, internette metalaştırılarak tüketildiğ $i$ görülebilmektedir. Örneğin bir Kabala, mistik bazı gizli ilimler, büyüsel sırlar metalaştırılıp ticarileştirilerek "satışa uygun" hale getirilebilmektedir. Bütün bunların yanında ise postmodern kimlikte "ilahi kutsal" arayışına özellikle yer verilmediği kolaylıkla görülebilmektedir. Bu "ilahi-vahyi" olanın kolayca tüketilemediğinden olacağı gibi küresel kapitalist sistemi değiştirme kabiliyetine sahip olması ile de alakalı olabilir ki bu da başka bir yazının konusu olacak kadar geniş bir konu hüviyeti taşımaktadır.

\section{Kaynakça}

Amant, S. St.(2003). Faith by Demonstration: The Connection Between The History of Paranormal Phenomena and a New Age Spirituality, State University of New York, College of Arts \& Science, Department of History (Basılmamış Doktora Tezi).

Arslan, M. (2010). “Paranormal İnanç Ölçeğinin Türkçe Versiyonunun Geliştirilmesi: Geçerlik ve Güvenirlik Çalışması", İnönü üniversitesi İlahiyat Fakültesi Dergisi, 1 (2): 23-40.

Arslan, M. (2011). Paranormalizm ve Din, Malatya: Bilsam Yayınları.

Bauman, Z. (1988) Postmodern Etik, (Çev. A. Türker). İstanbul: Ayrıntı Yayınları.

Beck, U. (1992). Risk Society Towards a New Modernity. London: Sage Publications. 
Bellah, R. (1981). "Religious Evolution", Sociology of Religion. (Ed. R. Robertson). Penguin Books Ltd. England: Harmondsworth.

Berger, P. (1993). Dinin Sosyal Gerçekliği. (Çev. A. Coşkun). İstanbul: İnsan Yayınları.

Çiçek, D. (1997). Postmodernizmin İslamcılar Üzerindeki Etkileri, Kayseri: Rey Yayınları

Giddens, A. (1994). Modernliğin Sonuçları (Çev. E. Kuşdil). İstanbul: Ayrıntı Yayınları.

Ong, W. J. (1995). Sözlü ve Yazılı Kültür, (Çev. S. P. Banon), İstanbul: Metis Yayınları.

Ritzer, G. (2000). Büyüsü Bozulmuş Dünyayı Büyülemek, (Çev. Ş. S. Kaya), İstanbul: Ayrıntı Yayınları.

Robertson, R. (2003). "Küreselleşme ve Geleneksel Dinin Geleceği". Dini Araştırmalar. (Çev. İ. Çapçıoğlu). 6 (17): 351-360.

Sherry, P. (2009). Disenchantment, Re-enchantment, and Enchantment, Modern Theology 25: 3, s. 369-386.

Sözen, Edibe, (1997). Medyatik Hafıza, İstanbul: Timaş Yayınları.

Weber, M. (1996). Sosyoloji Yazıları. (Ed. H.H. Gerth ve C.W. Mills; Çev. T. Parla). İstanbul: İletişim Yayınları.

Weber, M. (1976). The Protestant Ethic and the Spirit of Capitalism, New York: Charles Scribner's Son. 


\title{
MİLEL VE NiHAL
}

inanç, kültür ve mitoloji araştırmaları dergisi

Cilt/Volume: 12 Sayı/Number: 2 Temmuz - Aralık / July - December 2015 ISSN: $1304-5482$

Bu dergi uluslararası EBSCO HOST Research Databases veri indeksi ve TÜBITAK-ULAKBİM Sosyal ve Beşeri Bilimler Veri Tabanı tarafından taranmaktadır.

\section{Sahibi / Owner}

Milel ve Nihal Eğitim, Kültür ve Düşünce Platformu Derneği adına Şinasi Gündüz

\author{
Yazı İşleri Sorumlusu / Legal Representative \\ Yasin Aktay
}

Editör / Editor

Şinasi Gündüz

Editör Yrd. / Co-Editor

Cengiz Batuk

Hakan Olgun

\section{Sayı Editörü / Editor of Issue \\ Mustafa Tekin}

Yayın Kurulu/ Editorial Board*

Alpaslan Açıkgenç, Ayaz Akkoyun, Yasin Aktay, Mahmut Aydın,

Cengiz Batuk, Şinasi Gündüz, İbrahim Kayan, Hakan Olgun, Necdet Subaşı,

Burhanettin Tatar

\section{Danışma Kurulu/Advisory Board*}

Baki Adam (Prof. Dr., AÜ); Mohd. Mumtaz Ali (Prof. International Islamic U. Malezya); Adnan Aslan (Prof.Dr., Süleyman Şah Ü.); Kemal Ataman (Doç.Dr., Uludağ Ü.); Mehmet Akif Aydın (Prof. Dr., Marmara Ü.); Yılmaz Can (Prof. Dr., OMÜ); Ahmet Çakır (Doç. Dr., OMÜ); Mehmet Çelik

(Prof. Dr., Celal Bayar Ü.); Waleck S. Dalpour (Prof. University of Maine at Farmington); İsmail

Engin (Dr., Berlin); Cemalettin Erdemci (Prof.Dr. YYÜ); Tahsin Görgün (Prof.Dr., 29

Mayıs Ü.) Ahmet Güç (Prof.Dr., Uludağ Ü.); Recep Gün (Doç. Dr., OMÜ); Ö. Faruk Harman

(Prof.Dr., Mar.Ü.); Erica C.D. Hunter (Dr., Cambridge U.); Mehmet Katar (Prof. Dr., A.Ü.);

Mahmut Kaya (Prof. Dr., İ.Ü.); Sadık Kılıç (Prof.Dr., Atatürk Ü.); Şevket Kotan (Y.Doç.Dr., İ.Ü.);

İlhan Kutluer (Prof.Dr., Mar. Ü.); George F. McLean (Prof. Catholic Univ., Washington DC); Ahmet Yaşar Ocak (Prof. Dr., Hacettepe Ü.); Jon Oplinger (Prof. University of Maine at Farmington); Ömer

Özsoy (Prof.Dr., Frankfurt U.); Roselie Helena de Souza Pereira (Mestre em

Filofia-USP; UNICAMP Brasil); Ekrem Sarıkçıŏlu (Prof.Dr., SDÜ); Hüseyin Sarığlu (Prof.Dr.,

İ̈); Bobby S. Sayyid (Dr. Leeds U.); Mustafa Sinanoğlu (Prof.Dr., 29 Mayıs Ü.); Mahfuz Söylemez

(Prof.Dr. İ̈); Necdet Subaşı (Y.Doç.Dr., DİB); Bülent Şenay (Prof.Dr., UÜ); İsmail Taşpınar

(Prof.Dr. Mar.Ü.); C. Sadık Yaran (Prof.Dr., OMÜ); Ali Murat Yel (Prof.Dr., Fatih Ü.); Hüseyin Yılmaz (Doç.Dr., YYÜ); Ali İhsan Yitik (Prof. Dr., DEÜ)

* Soyadına göre alfabetik sıra / In alphabetical order

Kapak ve Sayfa Tasarımı / Cover \& Page Design İnan Avc1

Baskı / Publication

Ladin Ofset - İstanbul, Nisan 2016

2.Mat. Sit. 3 NB 15 Topkapı İstanbul / İsmail Tüz 02125012418

Yönetim Yeri / Administration Place

Milel ve Nihal Eğitim, Kültür ve Düşünce Platformu Derneği

Fevzipaşa Cad. Şehit Mehmet Sarper Alus Sok. No: 5, K.: 3, Tel: (0212) 5339731 Fatih/İstanbul www.milelvenihal.org e-posta: dergi@milelvenihal.org

Milel ve Nihal yılda iki sayı olarak altı ayda bir yayımlanan uluslararası hakemli bir dergidir. Milel ve Nihal'de yayımlanan yazıların bilimsel ve hukuki sorumluluğu yazarlarına aittir. Yayım dili Türkçe ve İngilizce'dir. Yayımlanan yazıların bütün yayın hakları Milel ve Nihal'e ait olup, yayıncının izni olmadan kısmen veya tamamen basılamaz, çoğaltılamaz ve elektronik ortama taşınamaz. Yazıların yayımlanıp yayımlanmamasından yayın kurulu sorumludur. 


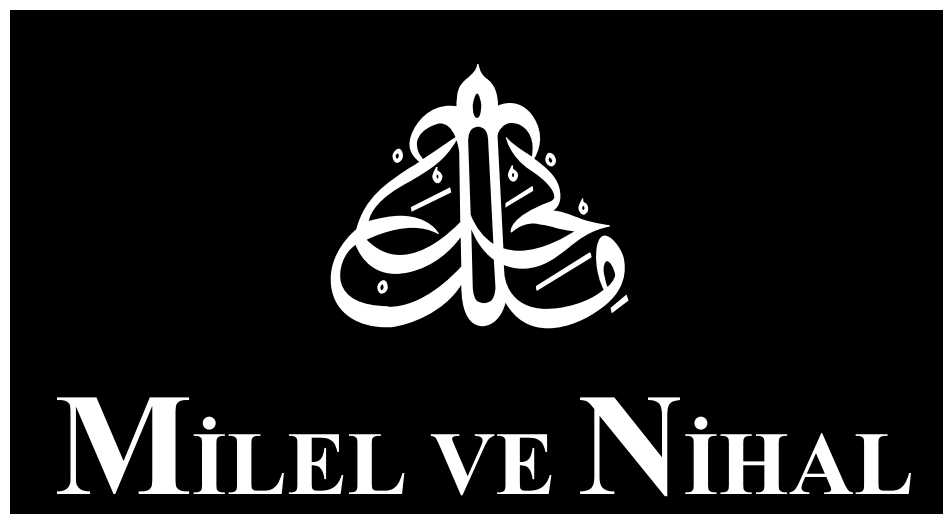

inanç, kültür ve mitoloji araştırmaları derģisi

ISSN: 1304-5482

DIN VE POSTMODERNIZMM

Cilt/Volume: 12 Sayı/Number: 2

Temmuz - Aralık / July - December 2015 
